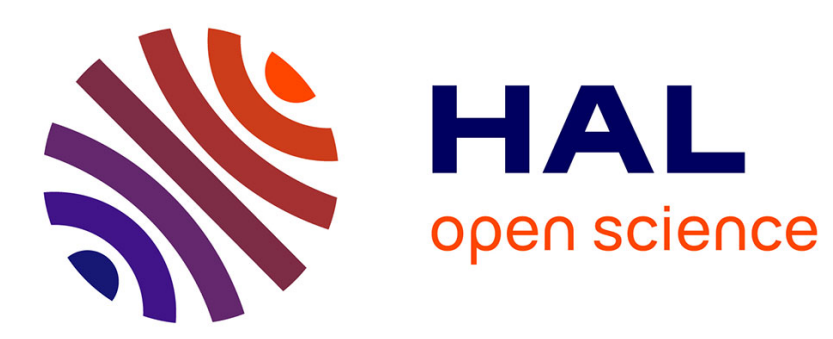

\title{
Optical properties of modified YAB single crystals : Y1-xLnx(Al1-yGay)3(BO3)4
}

\author{
N. Viegas, B. Teisseire, G. Aka, A. Kahn-Haradi, D. Vivien
}

\section{To cite this version:}

N. Viegas, B. Teisseire, G. Aka, A. Kahn-Haradi, D. Vivien. Optical properties of modified YAB single crystals: Y1-xLnx(Al1-yGay)3(BO3)4. Journal de Physique IV Proceedings, 1994, 04 (C4), pp.C4-357-C4-360. 10.1051/jp4:1994485 . jpa-00252748

\section{HAL Id: jpa-00252748 https://hal.science/jpa-00252748}

Submitted on 1 Jan 1994

HAL is a multi-disciplinary open access archive for the deposit and dissemination of scientific research documents, whether they are published or not. The documents may come from teaching and research institutions in France or abroad, or from public or private research centers.
L'archive ouverte pluridisciplinaire HAL, est destinée au dépôt et à la diffusion de documents scientifiques de niveau recherche, publiés ou non, émanant des établissements d'enseignement et de recherche français ou étrangers, des laboratoires publics ou privés. 


\title{
Optical properties of modified YAB single crystals: $\mathbf{Y}_{1-x} \mathbf{L n}_{x}\left(\mathbf{A l}_{1_{-} y} \mathbf{G a}_{y}\right)_{3}\left(\mathrm{BO}_{3}\right)_{4}$
}

\author{
N. VIEGAS, B. TEISSEIRE, G. AKA, A. KAHN-HARADI and D. VIVIEN
}

Laboratoire de Chimie Appliquée de l'Etat Solide, URA 1466 du CNRS, ENSCP, 11 rue P. et M. Curie, 75231 Paris cedex 05, France

\begin{abstract}
One of the best self frequency-doubling materials is $\mathrm{NYAB}, \mathrm{Y}_{1-\mathrm{x}} \mathrm{Nd}_{\times} \mathrm{Al}_{3}\left(\mathrm{BO}_{3}\right)_{4}$. Optical properties of isomorphous modified NYAB, obtained by gallium substitution to aluminum (NYAB-Ga) or $\mathrm{Yb}$ doping ion, are investigated.

Introduction
\end{abstract}

A way to develop solid state coherent sources in the visible range (blue-green) is the direct emission of visible light by internal second harmonic generation of the IR laser emission, thanks to the non linear optical properties of the matrix. One of the best self frequency-doubling materials is $\mathrm{NYAB}, \mathrm{Y}_{1-\mathrm{x}} \mathrm{Nd}_{x} \mathrm{Al}_{3}\left(\mathrm{BO}_{3}\right)_{4}$. $(1,2)$

Yet this material is still to be improved: NYAB crystals, prepared by flux methods, are not large $\left(5 \times 5 \times 10 \mathrm{~mm}^{3}\right)$. Moreover, this compound exhibits a $\mathrm{Nd}^{3+}$ absorption at $532 \mathrm{~nm}$, reducing the yield of the expected visible emission.

Therefore, isomorphous compounds, obtained by gallium substitution to aluminum (NYAB-Ga) or $\mathrm{Yb}$ doping of $Y A B$, are investigated in order to improve the crystal growth and try to minimize the re-absorption losses in the visible range.

I - Study of modified NYAB:

$\mathrm{Y}_{1-\mathrm{x}} \mathrm{Nd}_{\mathrm{x}}\left(\mathrm{Al}_{1-\mathrm{y}} \mathrm{Ga}_{\mathrm{y}}\right)_{3}\left(\mathrm{BO}_{3}\right)_{4}$

Gallium containing NYAB compounds, with $Y_{1-x} N_{d x}\left(A_{1-y} G_{y}\right)_{3}\left(B_{3}\right)_{4}$ general formula are obtained by solid state reaction, for $0<y<0.9 \mathrm{Ga}$ and $0<x<0.25 \mathrm{Nd}$.

Crystals are grown by a flux method, using potassium trimolybdate $\mathrm{K}_{2} \mathrm{MO}_{3} \mathrm{O}_{10}$ as solvent. Fairly perfect pink crystals of $\mathrm{Y}_{1-\mathrm{x}} \mathrm{Nd}_{\mathrm{x}}\left(\mathrm{Al}_{1-\mathrm{y}} \mathrm{Ga}_{\mathrm{y}}\right)_{3}\left(\mathrm{BO}_{3}\right)_{4}(0<\mathrm{x}<0.5)$ are obtained ( $\left.3 \times 3 \times 5 \mathrm{~mm}^{3}\right)$ with good optical quality. All crystals have hexagonal prismatic habits with rhombohedral structure (space group R32).

In NYAB lattice, the active neodymium ion is found on $Y^{3+}$ sites, in $D_{3}$ site symmetry, $\mathrm{Al}^{3+}$ ions in site symmetry $\mathrm{C}_{2}$. Boron ions are arranged in sheets of connecting $\left[\mathrm{BO}_{3}\right]$ triangles, perpendicular to [111].

Refinements of the NYAB structure performed, on single crystals, point out the modifications introduced around $\mathrm{Nd}^{3+}$ by the presence of gallium:

- Ln-Ln distances increase with increasing values of $y$

- Ln-O bond lengths increase with the Ga content, this suggests a weaker crystal field around $\mathrm{Ln}^{3+}$ active ion. This should be favourable to avoid quenching by cross relaxation process.-

The $B_{1}$ boron atom has a more symmetrical site than $B_{2}$, the environment of which undergoes more distortion when the Ga proportion increases.

\section{Optical study of $\mathrm{Nd}^{3}+$ in NYAB-Ga}

Experiments were conducted on NYAB-Ga crystals containing $30 \%$ gallium, for two $\mathrm{Nd}^{3+}$ compositions: $\left(\mathrm{Y}_{1-\mathrm{x}} \mathrm{Nd}_{\mathrm{x}}\left(\mathrm{Al}_{0.7} \mathrm{Ga}_{0.3}\right)_{3}\right.$ $\left(\mathrm{BO}_{3}\right)_{4}$ with $\mathrm{x}=0.05$ and 0.15 ). The optical behavior was compared to that of NYAB.

\section{1 - Polarized absorption measurements}

The $\sigma(E \perp c)$ and $\pi(E / / C)$ polarized absorption spectra recorded for NYAB-Ga present the same particularities as NYAB (fig.1). The $\sigma$ polarization spectrum is much more intense than for $\pi$ polarization. 


\section{3 - Fluorescence lifetimes}

Fluorescence decays of NYAB and NYAB$\mathrm{Ga}$ are exponential for all studied samples. In NYAB $-\mathrm{Ga}$, the ${ }^{4} \mathrm{~F}_{3 / 2}$ state luminescence lifetimes $\tau_{\text {lum }}$ are short $(48 \mu \mathrm{s})$, which is close to the reported NYAB $\tau_{\text {lum }}$ values (50$60 \mu \mathrm{s})$. Significant temperature dependence was not observed in the range $300-15 \mathrm{~K}$. The total radiative transition rate and the branching ratio for electric-dipole transition from ${ }^{4} \mathrm{~F}_{3 / 2}$ to ${ }^{4} \mathrm{I}_{\mathrm{J}}$ manifold were calculated. Branching ratios for NYAB-Ga are compared to those of NYAB in table III.

Table III- Branching ratios for $\left.4 F_{3 / 2} \rightarrow 4\right]_{j}$ transitions in NYAB-Ga and NYAB

\begin{tabular}{|c|c|c|c|c|c|c|}
\hline & & \multicolumn{3}{|c|}{ NYAB $\cdot G_{a}$} & \multicolumn{2}{|c|}{ NYAB } \\
\hline \multicolumn{2}{|c|}{ Transition } & $2(\mathrm{~nm})$ & $\beta_{\pi}$ & Bo & $B \pi$ & Bo \\
\hline${ }^{4} \mathbf{F}_{3 / 2}$ & $+4 / 9 n$ & 867 & 0,329 & 0.368 & 0.27 & 0.37 \\
\hline & $\rightarrow 4_{11 / 2}$ & 1063 & 0.522 & 0.500 & 0.56 & 0.50 \\
\hline & $\rightarrow 4_{13 / 2}$ & 1350 & 0.146 & 0.129 & 0.17 & 0.13 \\
\hline & $\rightarrow A_{15 / 2}$ & 1880 & 0.003 & 0.003 & 0.004 & 0.003 \\
\hline
\end{tabular}

The calculated radiative lifetime was found to be $\tau_{\text {rad }}=174 \mu \mathrm{s}$, whereas the radiative lifetime in NYAB is $\tau_{\mathrm{rad}}=267 \mu \mathrm{s}$. Hence, the quantum efficiency of ${ }^{4} \mathrm{~F}_{3 / 2}$ emission state in $\mathrm{Nd}^{3+}$ is about $27.4 \%$ in NYAB-Ga. The origin of this low quantum efficiency could be cross relaxation and/or non radiative transition.

- In the structure of NYAB-Ga, $\mathrm{Nd}^{3+}$ ions are shielded by the $\mathrm{B}-\mathrm{O}-\mathrm{Al}$ triangular prisms, and the Nd-Nd distance is relatively large $(5.908 \AA$ ). Therefore $\mathrm{Nd}-\mathrm{Nd}$ interaction should be weak (no cross relaxation).

- From 5 to $15 \% \mathrm{Nd}^{3+}$ content, no appreciable variations of the luminescence lifetime were detected (no concentration quenching).

The low quantum efficiency in these materials could then results from a multiphonon non-radiative process.

Absorption spectra show that partial replacement of $\mathrm{Al}^{3+}$ by $\mathrm{Ga}^{3+}$ ions in NYAB does not change the high energy phonons which are related to $\left(\mathrm{BO}_{3}\right)^{3}$-anions.

The largest observed phonon energy is about $1347 \mathrm{~cm}^{-1}$ and the energy gap $\Delta E$ between ${ }^{4} \mathrm{~F}_{3 / 2}$ and ${ }^{4} \mathrm{I}_{15 / 2}$ states is about $5400 \mathrm{~cm}^{-1}$. Therefore, the emission of only a few phonons with such energy is required to fill this energy gap.

A theoretical value of the $4 \mathrm{~F}_{3 / 2}$ luminescence lifetime was computed and the non-radiative emission rate evaluated, using the Reisberg and Moos theoretical approach (4) of multiphonon relaxation process. The resulting computed theoretical luminescence lifetime is $\tau_{\text {lum }}=49.9 \mu$ s (at $300 \mathrm{~K})$, which is very close to the experimental values $\left(\tau_{\text {lum }}=47.8 \mu \mathrm{s}\right)$.

This theoretical approach looks consistent with the non significant temperature dependence of the $\mathrm{Nd}^{3+}$ fluorescence lifetime. Therefore the low quantum efficiency in these materials probably arises from the non-radiative $4 \mathrm{~F}_{3 / 2} \rightarrow 4^{4} \mathrm{I}_{15 / 2}$ transition, which has a high probability, by emitting four $1344 \mathrm{~cm}^{-1}$ phonons.

\section{Discussion}

A partial substitution of $\mathrm{Ga}^{3+}$ to $\mathrm{Al}^{3+}$ ions in NYAB structure seems to induce positive effects, as listed in the following :

1 - Second harmonic generation from a pulsed $\mathrm{Nd}^{3+}$ : YAG laser has been demonstrated, using a NYAB-Ga crystal grown by flux methods.

2 - Oscillator strengths are higher in NYAB$\mathrm{Ga}$ than in NYAB. However, the ${ }^{4} \mathrm{~F}_{3 / 2}$ excited state lifetime is as short as the NYAB one.

3 - Ga substitution to $\mathrm{Al}$ induces a weaker crystal field around the active ion. $\mathrm{Nd}^{3+}$ fluorescence bands become broader when the gallium content increases in the host lattice. This corresponds to a structural disorder of $\mathrm{Nd}^{3+}$ environment and a lower Nd site symmetry, probably responsible for 


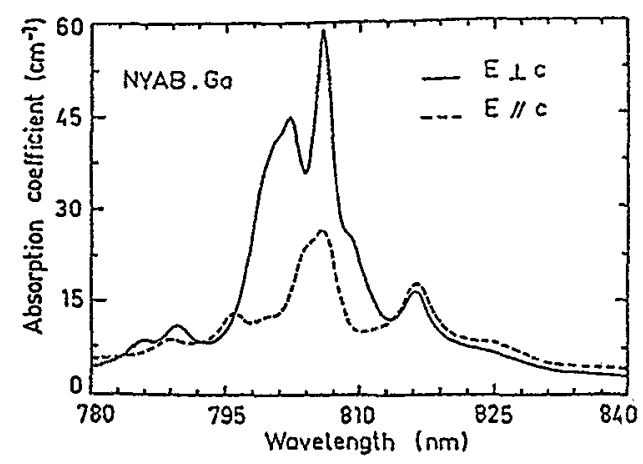

Fig 1 - Polarized absorption spectra of NYAB-Ga Nevertheless, the band peaking at $805 \mathrm{~nm}$ seems less sensitive to the direction of polarization.

The Judd-Ofelt intensity parameters are obtained by a linear least squares fit of the absorption line strengths using calculated reduced matrix elements between the states involved(3). Table I lists polarized intensity parameters as well as the $\Omega^{\text {eff }}$.

Table 1 - Judd-Ofelt parameters of $\mathrm{Nd}^{3}+$ in various host lattices at $300 \mathrm{~K}$ (units $10^{-20} \mathrm{~cm}^{2}$ )

\begin{tabular}{|c|c|c|c|c|c|}
\hline \multirow[b]{2}{*}{$\Omega_{\text {parameters }}$} & \multicolumn{3}{|c|}{ NYAB-Ga/NYAB } & \multirow{2}{*}{$\underset{i 5}{\mathrm{Ca}_{2} \mathrm{~A}_{2} \mathrm{SiO}}$} & \multirow{2}{*}{$\mathrm{Ca}_{(7)} \mathrm{Ga}_{2} \mathrm{SIO}$} \\
\hline & ters & $\sigma$ & eftective & & \\
\hline$\Omega_{2}$ & $1.70 / 1.13$ & $6.51 / 5.18$ & $4.91 / 3.83$ & 0.90 & 0.82 \\
\hline $\mathbf{\Omega}$ & $2.16 / 0.69$ & $4.66 / 3.52$ & $3.89 / 2.58$ & 3.40 & 2.41 \\
\hline$\Omega_{6}$ & $6.37 / 4.39$ & $9.22 / 6.81$ & $8.27 / 6.00$ & 4.90 & 6.44 \\
\hline RMS & $8.2110^{-8 / 5}, 5.04$ & \multicolumn{4}{|c|}{$0.28\left\{10^{-7 / 7.12}, 10^{-7}\right.$} \\
\hline
\end{tabular}

This suggests that a laser diode could be used to pump NYAB-Ga crystals. In addition, to minimize re-absorption losses an efficient end pumping scheme of NYAB$\mathrm{Ga}$ at $806 \mathrm{~nm}$ should be done with $\pi$ polarization.

2 - Fluorescence measurements

Polarized fluorescence measurements and lifetime measurements look very similar for NYAB and NYAB-Ga (fig. 2).

The main fluorescence peak is centered at $1.063 \mu \mathrm{m}$ for $\sigma$ and $\pi$ polarizations and, in both compounds, the $\sigma$ emission is more intense than the $\pi$ one. Nevertheless, the NYAB-Ga emission is less sensitive to polarization than the NYAB one, for which the intensity decreases dramatically with $\pi$ polarization. Moreover, the spectral widths are slightly broader in NYAB-Ga. The emission cross section is of the same order of magnitude in NYAB-Ga and in NYAB., as shown in table II.

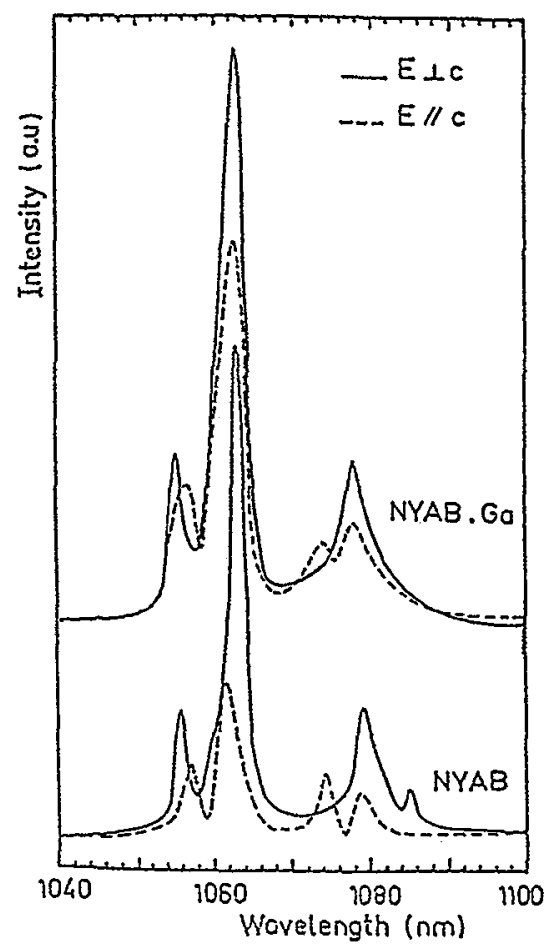

fig.2 - Polarized fluorscence spectra of NYAB-Ga and $N Y A B$ at $100 \mathrm{~K}$, for the ${ }^{4} F_{3 / 2} \rightarrow{ }^{4} I_{13 / 2}$ transition

This confirms that a partial substitution of $\mathrm{Ga}^{3+}$ to $\mathrm{Al}^{3+}$ ions induces positive effects on the material optical behavior.

Table Il - Optical parameters for NYAB-Ga,

\begin{tabular}{|c|c|c|}
\hline Parameters & NYAB-Ga & NYAB \\
\hline$\left.\sigma_{e}(\mathrm{~cm})^{2}\right) \pi$ & $1.2810-19$ & $1.2510^{-19}$ \\
\hline$\sigma$ & 2.4710 .19 & $2.6010-19$ \\
\hline Nd concentr. & 8.161020 & 8.401020 \\
\hline$\tau \operatorname{rad}\left(4 F_{3 / 2}\right)$ & $174 \mu s$ & $267 \mu \mathrm{s}$ \\
\hline $\begin{array}{l}4 F_{3 / 2} \text { quantum } \\
\text { efficiency }\end{array}$ & $27.4 \%$ & $17.3 \%$ \\
\hline
\end{tabular}




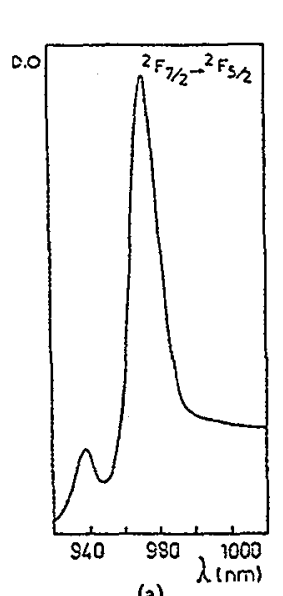

(a)

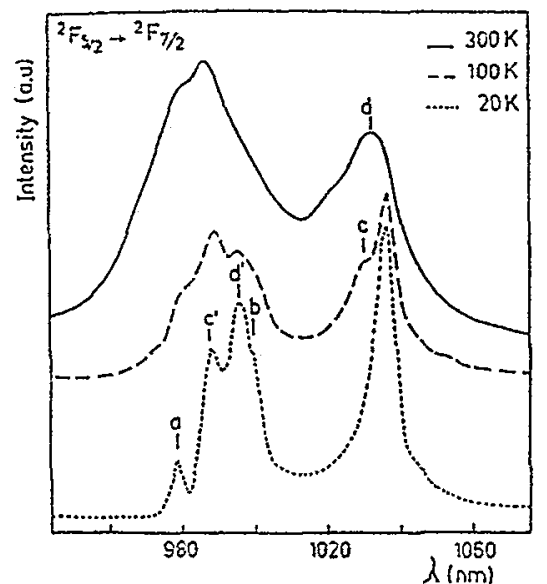

(b)

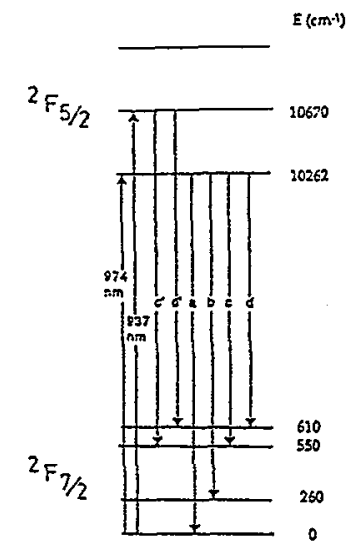

(c)

fig.3-absorption(a), fluorescence (b) and energy-Ievels diagram(c) of Y ${ }^{3}+$ doped YAB crystals

the admixture of odd-parity transitions into the $4 f^{3}$ configuration of $\mathrm{Nd}^{3+}$.

All these results suggest that $\mathrm{Ga}^{3}+$ ions do not alter the optical properties of NYAB-like crystals. NYAB-Ga crystals could be pumped efficiently with a laser diode. In addition, to minimize re-absorption losses at $532 \mathrm{~nm}$, during a self frequency doubling laser test, the most efficient end pumping scheme of NYAB-Ga should be done with $\pi$ polarization.

\section{II - Optical study of $\mathrm{Yb}^{3}+$ doped $\mathrm{YAB}$} $\mathrm{Yb}^{3+:} \mathrm{YAl}_{3}\left(\mathrm{BO}_{3}\right)_{4}$ is studied to evaluate its emission and absorption properties in order to assess the potential self frequency doubling performance of this material. Indeed, $\mathrm{Yb}^{3+}$ is ideally suited for diode pumping, since it has quite a simple energy -level diagram to be used in a laser system. Large size crystals $\left(7 \times 7 \times 5 \mathrm{~mm}^{3}\right)$ of $\mathrm{Yb}^{3+}$ doped $Y A B$, of good optical quality, have been grown by a flux method $\left(Y_{1-x} Y_{x} \mathrm{Al}_{3}\left(\mathrm{BO}_{3}\right)_{4}\right.$, with $\left.\mathrm{x}=0.05,0.02,0.15\right)$.

The absorption band around $480 \mathrm{~nm}$ (fig $3 \mathrm{a}$ ) is quite broad (FWMH $=19 \mathrm{~nm}$ ). It means that thermal requirements on the pumping laser diode would be less drastic than in Nd:
YAG for example. The computed value of oscillator-strentgh at $974 \mathrm{~nm}$ is $3.29 \times 10^{-6}$. Fluorescence spectra are given in fig. $3 \mathrm{~b}$ from 300 to $20 \mathrm{~K}$, with a good resolution of the $2 \mathrm{~F}_{5 / 2} \rightarrow{ }^{2} \mathrm{~F}_{7 / 2}$ transition at $20 \mathrm{~K}$. The main peaks are around 1000 and $1035 \mathrm{~nm}$. $\mathrm{Yb}^{3+}$ energy level diagram in $\mathrm{YAB}$ is given in fig. $3 \mathrm{C}$ and $Y \mathrm{~b}^{3+:} Y A B$ is a quasi four-level system. Compared to other $Y b$ doped matrices, this one shows a very narrow overlapping between absorption and emission wavelength ranges. The main emission line at $1035 \mathrm{~nm}$ would result in a visible emission at $517 \mathrm{~nm}$ by self doubling frequency, where no re-absorption occurs.

Therefore $\mathrm{Yb}^{3+} \mathrm{YAB}$ non linear matrix could offer a number of advantadges in a self frequency doubling operating laser.

\section{REFERENCES}

1-T. Y. Fan and R. L. Byer,

IEEE J. of Quantum Electronics 24 (1988) 895

2-M. W. Qui, Y. C. Huang A. D. Jiang, and Z. D. Luo, "Self-frequency doubling minilaser device with NYAB crystal as laser materials, "U.S. patent No $5,058,118$ (1991).

\section{3- W. T. Carnall,P.R. Field, K. Rajnak,}

J. Chem. Phys. 49 (1968) 4424

4-L.A.Riseberg W. H. Moos,Phys. Rev., 174, 429 (1968) 